\title{
Producing Knowledge in Self-Organized Artistic Settings through Performative Research and Artistic Intervention
}

\author{
Hanne Seitz
}

\begin{abstract}
The following article presents the Young Tenants, a project that gave young Berlin adults the opportunity to use vacant spaces for art and culturerelated purposes. Through organizing and participating in activities in these spaces they discovered their artistic creativity and craftsmanship, practiced cultural participation and engaged with the community. In contrast to what they typically experienced in school or in out-of-school education, the project emphasized selforganization and an environmental approach towards learning. The accompanying research called for a different logic of enquiry than in the usual discursive mode of qualitative social research. The tenants were regarded as coresearchers, capable of finding creative solutions for the problems that arose while working towards the goals they had set for themselves. They produced knowledge through their art making, which was expanded, transformed and renewed through a practice-based action research process. At the same time, since understanding is not always reducible to language, we focused on their actions as expressions of embedded knowledge and considered the project to be a practice-led performative research. Additionally, we unlocked further potential though artistic interventions that served to enrich their activities, deepen reflection, and challenge the knowledge generated.
\end{abstract}

Why is the classroom the main place where lessons take place - who decided that?

More community life on the streets, more participation!

More places where young people can easily showcase their creative work.

(Statements from peer-to-peer interviews, Kulturprojekte 2010)

\section{Berlin youth demand self-organized artistic settings}

In a peer-to-peer survey, conducted in 2010, over 300 youngsters and young adults from all over Berlin were asked about their understanding of art, their interest in creative activities and cultural education programs. They emphasized the shortage of public spaces for young people and complained that (aside from 
streets, fallow wastelands or shopping malls) the only uncomplicated and easily accessible space was the internet. Social networks involve no major expenses and offer platforms which give young people visibility, but they also create a constant pressure to perform and to be up to date at all times. The interviewed youngsters therefore expressed a need for analogue forms of communication that facilitate a deeper and more meaningful facetoface exchange. Instead of availing themselves of the virtual options provided by the digital media, they wanted to step onto real stages and engage with the physical world of bodies, materials and spaces.

In response to the survey, the young interviewers established the 'Young Council' (Junger Rat) and organized a youth conference aimed at investigating potential forms of active participation for them in the area of art and culture. Most of the conference members felt that school was not an appropriate place for the sort of creative work they had in mind. Being suspicious of all kinds of educational settings they even hesitated to take up opportunities offered by cultural institutions, e.g. museums, theatres or literature houses. Many of them held prejudices against 'highbrow culture' and associated it with old paintings, dusty museums, longwinded theatre performances, boring concerts, dry lectures and, as they put it, cultural events for "artzealous middleclass bores". And those who had already participated in one of those cultural educational programs felt that it had just followed a foreseeable template. They explicitly criticized the fact that the organizing adults who had encouraged the youngsters to participate had in fact strategically 'used' the interaction with them to realize their own project aspirations. Moreover, they felt that such regularly offered programs were not 'artful' enough and often functioned as a 'social repair kit'. The conference participants stated that their own creative endeavor and specific style was not sufficiently acknowledged or even considered to be of artistic value.

The discussions at the conference on basic questions about art and culture were controversial and emotionally guided, but all participants agreed that there was a need for cultural and artistic experiments and a closer engagement with the environment. They asked for a framework that would enable them to become independent and responsible and give them an opportunity to engage in active citizenship. The conference participants finally adopted a kind of manifesto. Their list of demands, addressed to Berlin's City Council, was quite long. It is noteworthy that the first item on the list was their wish to be trusted with the responsibility to run selforganized spaces for artistic and creative activities, i.e. rooms designed by themselves where they would share their skills and creative practices with others and also showcase their cultural achievements for the wider community. After having received broad public attention for being the initiator of the conference, the Young Council started to play an increasingly successful mediating role between young people, cultural institutions, and politicians. And finally, their demand for selfregulated spaces was met. The Berlinbased Internationales JugendKunst und Kulturhaus Schlesische27 which had helped to organize the peer-to-peer survey and provided the space for the 
youth conference, reacted to the needs by facilitating a project called Young Tenants (Junge Pächter). ${ }^{1}$

Kreative Köpfe // A vacant pub in the Spandauer Neustadt, - a neighborhood in Berlin which has not yet been earmarked for gentrification. Young people furnish the space, start an improvisation theatre group, run a creative writing workshop and set up a photo studio. The activities in this longterm vacant space are being critically observed by the neighbors. The project starts with an opening event at which around 80 young guests are introduced to the forthcoming initiatives. Someone who thinks the invited band is playing too loudly has apparently called the police. The officer, however, remains friendly and finds that the music is hardly louder than the noise coming from the busy street outside: "Oh, I see, it's a youth project sponsored by the Berlin City Council, well that's okay then." It hardly comes as a surprise that, later on, the son of the policeman joins the improvisation group and even the officer himself at some point shows an interest in the various activities going on in the space. The members of the photo group, for example, manage to recruit a friend who is a makeup artist in a theatre. They start to provide a special portrait service for their friends, families and occasional passersby. Famous actors from the world of film serve as a source of inspiration for the somewhat unusual, quirky portraits which the group will show later on in an exhibition.

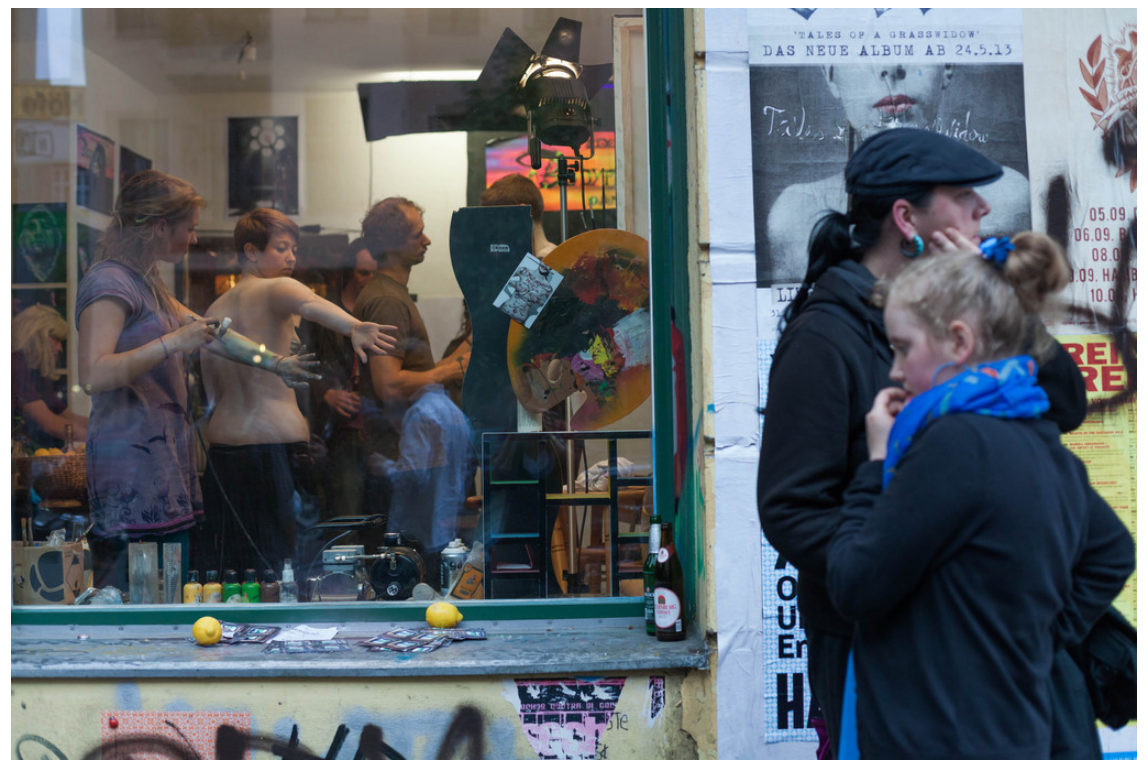

Figure 1: Fig. 1. "Schlesi19", tenant space in Berlin-Kreuzberg (@ Schlesische27).

\footnotetext{
1 Parts of this and the following two chapters have been published in German (Seitz Steinkrauss 2013).
} 


\section{Creative practice performed by young tenants}

Being a non-formal and out-of-school education institution in the cultural field, the Schlesische27 normally offers arts and crafts courses, projects and workshops for children, youngsters and young adults. In the case of the tenant project, it set up what might be called a 'program without a program'. This included the handing over of unoccupied sites to young adults (most of them aged between 17 and 25) in six city districts. For a limited period of time they were given the opportunity to use deserted shops, empty pubs, an old carriage house, etc. in those districts to perform their own artistic and cultural endeavors - small events for friends and youngsters in the immediate neighborhood and possibly from other parts of the city. The tenants received a small budget and were given full responsibility for their spaces - on the condition that they would work on a cultural concept, give themselves house rules, make a financial plan, and invite the public at least once every three months to certain events.

The project started in 2011 and ended in 2014 and ran over three cycles (each year from September to June). New members were allowed to join at the start of a new cycle, which typically began with a so-called project forge (Projektschmiede) at Schlesische27, when around 80 young people from all over Berlin from different social backgrounds met for a twoday workshop. During these two days they were introduced to cultural pilot projects and artistic initiatives (like the architect group Raumlabor, or the members of Prinzessinnengärten that ran the first urban gardening initiative in Berlin). They offered an inspiring range of ideas as well as a forum for mutual exchange. The young adults also got an insight into organizational and technical issues, such as conflict management, legal issues, budgeting, public relations and the intermediate use of urban spaces.

The participants discussed their ideas at the project forge in randomly formed groups and in creative workshops, developing and designing their 'hotforged plans' (Heißschmiedepläne) to arrive at initial mutual agreements. They used a wide range of materials to build models and threedimensional objects which were then displayed on doorsized big black wooden panels to visually express their ideas for the use of their spaces: surreal places, e.g. connecting a cinema, an office for social design, a photographic lab, and an outdoor area for urban activities. Witty and creative names for the future spaces were found: Machwerk, Heim(e)lich, Photosphaere, Kreative Köpfe, Dorfplatz Untertage, SpaceShuffle, etc. In the second cycle the project forge started with a floor plan of six rooms in the so-called Red Hall at Schlesische27, each one representing a tenant space. The tenants of the first round furnished them with one or two items (an armchair, a lamp, a kidneyshaped coffee table from the 1950s, etc.) which attracted the newcomers into the space. Here they began to discuss their visions of a possible usage and, again, presented this on a wooden panel.

The young people who got involved in the tenant project were ambitious, courageous, full of energy, and ready to tap into their creativity in order to serve 


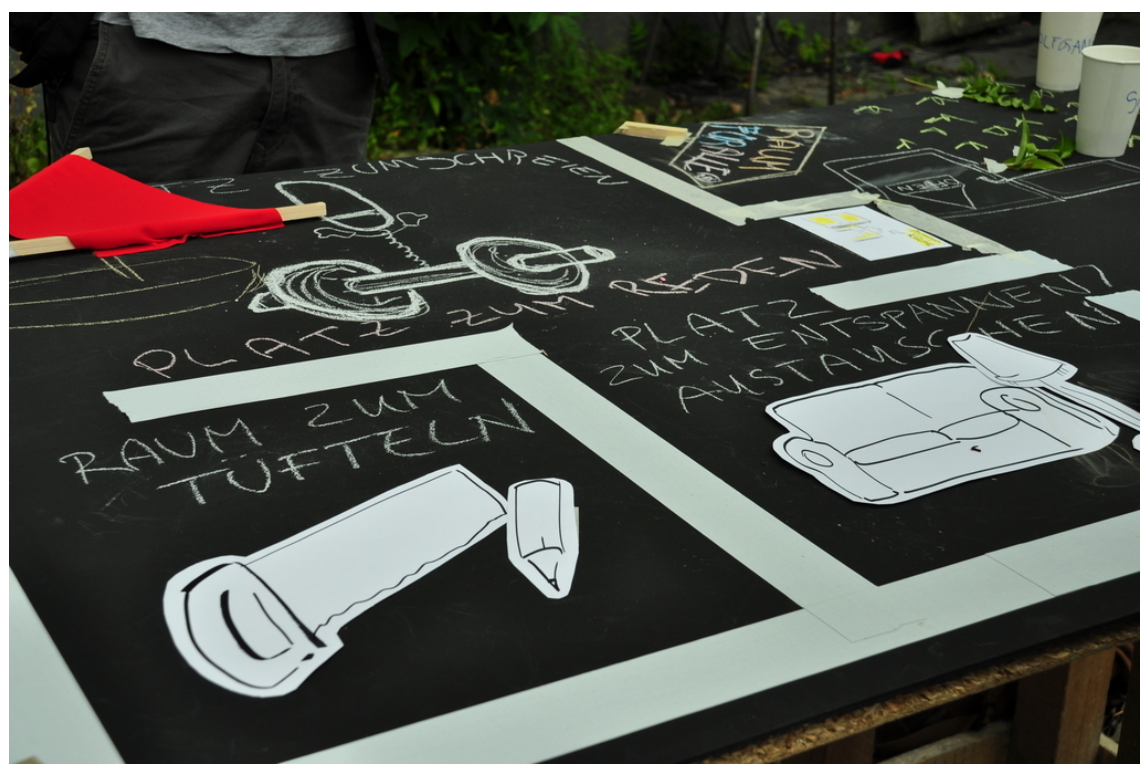

Figure 2: Fig. 2. Planning spaces at the project forge (@ Hanne Seitz).

what they perceived as the cultural needs of the wider public. They gradually became promoters and hosts while developing their projects and workshops, including the PRrelated work. The Schlesische27 engaged professionals dealing with theatre, music, dance, visual arts, or film from various cultural institutions in Berlin to support them, e.g. the Neuköllner Oper, Arsenal Institut für Film und Videokunst, Tanzwerkstatt DOCK 11, Schlossplatztheater Köpenick, JugendTheaterWerkstatt Spandau. However, these mentors gave technical, organizational and artistic advice only when the young people explicitly requested this kind of assistance. Working together with the mentors meant that the young tenants could also become more aware of different career profiles in the cultural sector and gradually develop a better understanding of professional working conditions and standards.

Dorfplatz Untertage // Small, handwritten signs point the way through the meandering (under)grounds of a former brewery in Neukölln. They lead downstairs into a dimly lit hall, which seemingly disappears into the catacombs of this old site. On the left a door opens to a theatre space with old carpets, a hotchpotch of chairs, a stage, a lighting control desk and a bar. Someone is rehearsing. Two corridors further down is a spacious room that surprisingly offers daylight and a good view from within this building situated on a hillside. In the middle is a selfbuilt kitchen and there are also some reclaimed sofas. This room serves as a meeting place for the young tenants who have set themselves up in the adjoining rooms. Ten tenants are having a first go at their adaptation of Gertrude Stein's "Dr. Faustus Lights the Lights": a Dadaistic collage called "Dr. Faustus Lichterloh" focusing on the difficulty of communication. The choir that rehearsed here the day before has almost 50 members and will soon give an openair concert. In another room a tenant is surrounded by instruments 
made of junk: different kinds of buckets, sculptures shaped out of sheet metal, a bass whose strings are made from the type of wire used for bicycle brakes. The vibraphone is made out of plastic tubes and is played with flipflops. This does not only sound nice, but also looks good. The music lifts the spirits of the group in the kitchen who is cooking chili con carne; on today's menu is a hot and very spicy meal.

\section{Producing and sharing knowledge in tenant spaces}

After getting the keys, the tenants began the renovation and design of their premises. In some cases this turned out to be very tedious. A bazaar at Schlesische27 provided them with their first items of furniture. Other things they needed were supplied by sponsors or borrowed, free of charge, from supportive individuals, including the mentors. A wide range of activities were developed in the tenant spaces: handicraftoriented projects, performances, theatre or musical events, workshops, poetry slams and, in one case, the tenants even explored the 'art of living' in the manner of the avantgarde aesthetics wanting to fruitfully merge art and life in order to contribute to artistic and social progress.

Networking between the different groups in the rooms and also among members of the tenant spaces in the other city districts generated contact between different communities and youth cultures. Friends and residents in the neighborhood were encouraged to participate in the young tenants' projects. In the beginning, the tenants were not keen at all on asking for help or learning from the expertise of their mentors. The young tenants felt professional enough to work independently and make their own arrangements. In doing so they sharpened their ability to perceive but also their capacity to produce, thus realizing what the ancient Greek called aisthesis and poiesis. Their learning took place outside of any formal educational services, in environments which posed far greater challenges and were much closer to reality than in any school context. The tenants learned to come up with creative solutions and act responsibly in contexts which really mattered to them.

At the general meetings, which were held in the tenant rooms, the young people shared their ideas, their knowledge and, invariably, negotiated personal values and preferences. The discussions were both unsettling and reassuring, but they always resulted in the tenants reflecting on and reviewing their own points of view. It was particularly in situations of conflict that they realized a democratic approach cannot be taken for granted, but that it actually needs to be repeatedly practiced and re-negotiated. There was no prescribed structure or list of functions. The tenants themselves were in charge of formulating the criteria which were to form the basis for how their project was managed. Nobody controlled them, or checked, for example, if the law on protecting minors was observed or the property was used in an appropriate way. Having been trusted with responsibility is perhaps the very reason why the young tenants did not abuse this trust. 


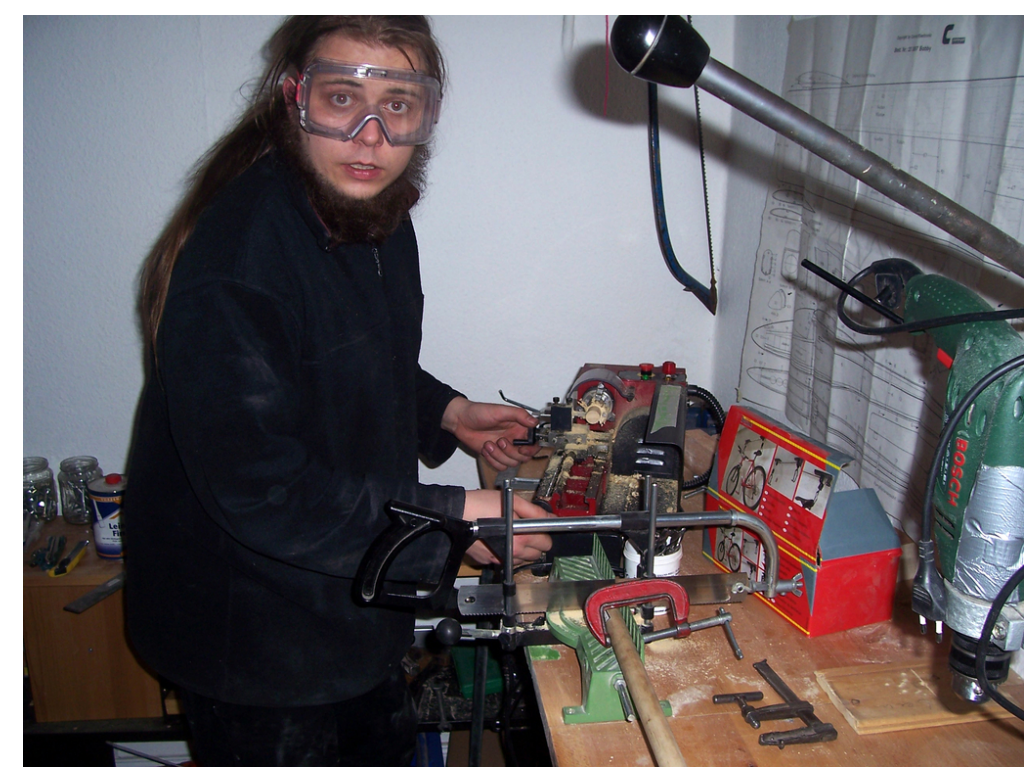

Figure 3: Fig. 3. "Machwerk", tenant space in Berlin-Wedding (@ Schlesische27)

In the beginning they were happy enough amongst themselves, but the more the project developed, the more they overcame their inward orientation; they seized the opportunity to become visible, go public and leave their mark. It was inevitable that this involved a great measure of conflict (e.g. with neighbors). The generally functional orientation of adults contrasted with the young people's desire for a playful and sometimes anarchic rearrangement of their spaces and the use of uncommon and somewhat subversive strategies. Similar to a 'bricolleur' they took apart what was given and used the elements to construct something different. The functions of 'inherited' objects, e.g. an old sign on the façade, a counter, an empty tool rack, and some oldfashioned wallpaper were creatively converted. There seemed to be no end to the imagination of the young tenants who, again and again, came up with yet another unconventional use of their spaces.

Having been trusted with responsibility and appreciating the exceptional opportunity to organize themselves, the tenants were soon keen to defy the clichéd image that is often associated with youngsters, i.e. that they are inconsiderate, unproductive, and even destructive. They were, for instance, concerned about their neighbors and willing to listen to them when they said they felt disturbed by the noise levels in the tenants' spaces; they gave a hand when children in the neighborhood needed help with the repair of a bicycle, and they showed a sense of responsibility for the correct disposal of the chemical liquids they used to develop analogue photographs with. Regarding the wider political context, they shared a deep concern for people who find themselves in lifethreatening situations in the Mediterranean and questioned the existing European asylum policies. In their theatre piece "Dr. Faustus Lichterloh" light played an important role, which was understood as a key metaphor for the 
empowerment of the young people - the 'illumination' of their practices.

Looking back over three project cycles, it seems that the tenants got what they had asked for: a space to develop and share their own ideas and where they could offer creative workshops, produce cultural programs and sitespecific events. And, speaking of light, it is noteworthy that the young people often were in the public spotlight. Their projects were met with approval in radio features, newspaper reviews and various other publications. The cultural department of the Berlin Senate even invited them to participate in a discussion on youth and urban culture, and the Federal Government Commissioner for Culture and the Media honored them with an annually awarded prize, the BKMPreis Kulturelle Bildung 2013. And, last but not least, the tenant project was acknowledged as an example of 'best practice' within a European research network.

Machwerk // The tenant space is located in Wedding, a former working class district of Berlin. People are welcomed and invited to enter the space. Tools and pieces of used wood and wood shavings are everywhere and in the corner is a workbench and a rack with bicycle parts. A coffeestained list of house rules is pinned on the wall. At the table with a selfconstructed silk screen printing device someone is printing Tshirts with the Machwerk-logo: a flame and a spanner. In the centre of the room is a jackedup bicycle. Numerous generators are connected to a circuit board which is connected to an amplifier and to selfmade speakers supplied by the 'electro cave' where, according to the tenants, "rickety old bikes are converted into knight riders". A guest is pedaling as fast as he can to operate a nail connected to a circuit board and the bike does what it is expected to do: it creates noisy sounds. It will be used at a forthcoming political demonstration, and the team of Schlesische27 wonders: is this art or is this a political statement as part of an unauthorized demonstration?. The compressor, bought from the budget, is whirring away and labyrinthlike tangled tubes are blowing the air past the small kitchen into the rear courtyard where some are busy with the cleaning of silk screens.

\section{Performative research and artistic intervention}

The research carried out by the University of Applied Sciences Potsdam (FHP) explored the possibilities of selforganization and selfempowerment within the tenant project and introduced it to the European network "Empowering the Future. Youth, Arts \& Media" (ETFU). Within this network "power labs" from four European countries (consisting of members of cultural agencies and universities) conducted research on what was best practice, and developed methodologies and a training program for professionals and organizations with a keen interest in evaluating and improving their work with youngsters and young adults. ${ }^{2}$

\footnotetext{
2 The German research group was led by Nils Steinkrauss, Project manager at Schlesische27, Julia Riedel, research assistant at FHP, and myself. The results from all ETFU-power labs and the training modules will be downloadable by the end of 2015 under www. et fu.eu. The research reports written (in German) by students from FHP, a flyer and video concerning
} 
The Potsdam-Berlin power lab aimed to focus its research on the practices of self-organization and the further improvement of these practices. While student researchers from FHP conducted participant observation in the tenant spaces, arranged interviews and wrote reports on their findings, the power lab team invited volunteering tenants to the 'Pärflexionmeetings' (a wordplay on Pächter, Perzeption, Reflexion), where they were regarded as coresearchers. They were introduced to how they could plan, observe, and reflect on activities using an action research model, and explore their practice in terms of an interplay between aims, reflection and action. At first, being primarily focused on their activities, the tenants were not interested in this kind of research, but gradually got engaged and prepared the meetings in cooperation with the facilitators of Schlesische27 and, later, sometimes even called them 'PAC-meeting' (an acronym from Pächter, Action and Vitamin C), which sounds like 'pack', a word signifying a cool gang, but (in German) also meaning to grab, to seize or tackle something.

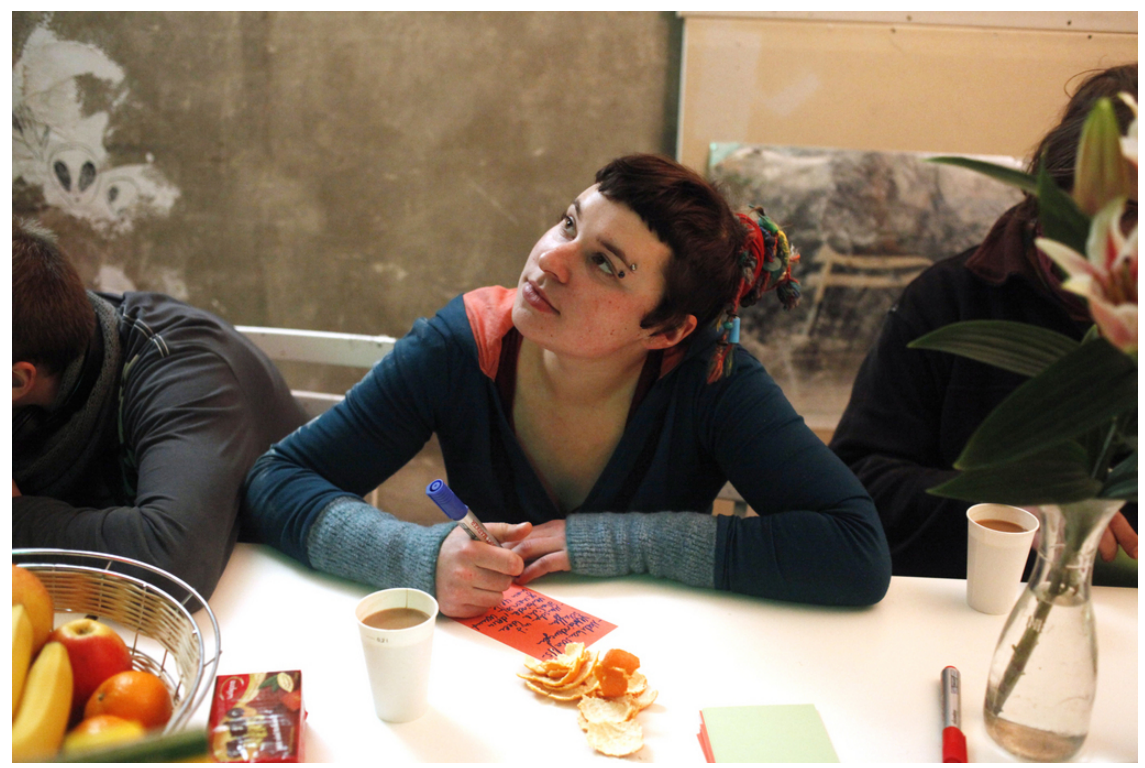

Figure 4: Fig. 4. Tenants at a Pärflexionmeeting (@ Schlesische27).

The knowledge gained in qualitative social research usually takes retrospective account of practice and is generated in discursive settings. The tenant project, however, seemed to call for a different logic of enquiry. First and foremost, the research was not understood as a collection and analysis of data gained only by the observation of practice or by interviewing the practitioners. It was meant to highlight the practice itself as research and understood research as the driving force that pervades the practice itself - what Brad Haseman (2007) calls a "practice-led" approach. The tenants accomplished the goals they had set for

their view on the tenant project can be retrieved under www. fh-potsdam. de/projekt/projectaction/show/Project/etfu-empowering-the-future-youth-arts-media/. Further information and videos concerning the tenant project are available under http://junge-paechter. de. 
themselves on the basis of the knowledge they had - implicit, tacit knowledge and practical ability and, therefore, a knowledge that is embedded in the practice. But the tenants also gained new knowledge, because their practices, at times, required research at a very basic level: they compared, analyzed, reflected, established preliminary hypotheses, proved their practicability, and solved problems while they were doing what they were doing. Our research therefore considered both the knowledge embedded in the practice and the reflection that came about while processing, dealing with, and handling practice -so-called "knowledgeinaction" and "reflectioninaction" (Altrichter et al. 2008: 271 f.). Occasionally, especially in situations of conflict, when complications had arisen and there seemed to be a discrepancy between purported desires and actual effects, activities had to be explained and negotiated. In such cases neither their practical ability nor their trying out 'in action' was sufficient. The tenants needed to step aside and separate the thinking from the doing and "reflectonaction" (ibid. 273). This is an essential prerequisite for any action research and practice-based approach and explicitly for the Pärflexionmeetings, which aimed to undertake inquiry at eye level in order to improve the work - hereby following (and repeating) an "action research cycle", which involves observing, reflecting, planning and acting (Whitehead 2015, Altrichter et al. 2008).

Against this background, the research our power lab conducted in order to gain and conceptualize knowledge about self-organized approaches to good practice called for a distinction between word-based theory about practice and 'practice as it is'. In doing so we considered what Susanne Langer calls presentational and discursive symbolization (Langer 1965). Presentational symbolizations (video, photo, music, theatre, dance, poetry slam, etc.) express implicit and explicit knowledge (that one knows and reflects upon while practicing), whereas discursive symbolizations use language (discussions, interviews, notebooks, questionnaires, Sudelbücher, etc.), reflect and expedite knowledge (that one reflects upon and speaks about through looking at the practice). Therefore, on the one hand, we listened to what the tenants had to say about their activities and, on the other hand, we focused on the products and processes, looking at what the tenants actually did and showed. In the latter case, the work 'speaks for itself' and inscribes understanding and new insights right into the practice and aspires to be one with it. Here, the knowledge is disseminated and depends upon the act of performed practice and the products deriving from it. It is not expressed in discursive language but in presentational symbolic 'data' which need no textual representation and therefore preserve the complexity of practice, retain its openness, and capture what one may not be able to say, but show. We conceptualized this approach to practice as performative research (Seitz 2012). ${ }^{3}$

\footnotetext{
${ }^{3}$ Seitz (2012) gives an overview of this new research paradigm. Please note that an English version will appear in: Schewe, Manfred Even, Susanne (forthcoming): Performative Teaching, Learning, Research. Berlin: Schibri Verlag.
} 
It goes without saying that our power lab (and particularly the students from FHP) also conducted practice-based research, used traditional social scientific methods, e.g. interviews, group discussions, participant observation, wrote transcripts and minutes, etc. Our observations, inquiries and findings were theorized and put into writing for the final ETFU-Report. Still, the primary aim of the methodology was indeed to focus on practice-led research. Yet, looking at what happened in practice, we observed that the tenants often felt confident, sometimes even complacent with what they were doing. They hardly ever asked their mentors for professional advice or critique. They were keen to perform and 'knew' how to do it - to stage themselves and to showcase their work. At times we felt the tenants should be more self-critical and question the substance and content of their activities. We did not want to interfere directly, especially not verbally (knowing, of course, that our mere presence was already an interference). But since the objective of the research process was to push forward existing know-how and impart new knowledge and understanding, our power lab came up with the idea of artistic interventions, in other words, with unexpected presentational symbolizations supplied from the outside. The impulses did not steer the tenants in a certain direction, nor were they directly linked to their activities. They were meant to deepen phases of reflection and aimed at questioning the value of complacent activities, and at making tenants aware of habitual behavior patterns. This was achieved through what we called "reflectionasideaction". Such an intervention could be, e.g. listening to strange music composed by Morton Feldman, holding a Pärflexionmeeting in an unusual spatial setting designed by the architects of Raumlabor, showing photo portraits made by the artist Cindy Sherman, or watching the video of Marina Abramovic' performance "The artist is present". The latter, for instance, touched the young people on an emotional level and gave them a sense of what it means to act and to be oneself in relation to others. They began to understand that artistic practice does not need to be flamboyant, sensational, or loud, but can simply be 'doing nothing': just being attentive and present.

Photosphaere // The photography on the grey wall shows the tenants huddling together in their sleeping bags. The oldfashioned stove in this former coach house in Pankow heats charmingly, but ineffectively in the cold winter in Berlin. From an urban point of view, this is an experiment conducted in extreme conditions for the young pioneers who endeavor to realize an idea that the avantgarde artists had explored before. For three months, six young people live and work together, investigate their urban environment and document their very own experiments. The photos and videos, texts and manifests, paintings on canvas and images on their own bodies will later be part of an exhibition to which the public is invited. Artists, friends and neighbors come to their Open House on Sundays. An old Olympia typewriter encourages spontaneous writing, and paint and cameras call for artistic use. It's Christmas. 'Creative cookies' are baked and one of the walls is completely decorated with wish lists. 


\section{Environmental approach and informal learning}

Becoming involved as coresearchers and thus becoming more familiar with an academic setting was not really the tenants' main concern. They were preoccupied with their projects and it is unlikely that they would ever have organized a Pärflexionmeeting on their own. But, gradually, they appreciated the challenge and potential benefits of reflecting and looking at their actions from a more distanced point of view. Some of the tenants were even interested in reading the research reports the students from FHP had written, or one of the articles that had been published on the project (e.g. Seitz \& Steinkraus 2013). They never felt that they were learning, rather they remained suspicious of anything that reminded them of the kind of education they had experienced. We interpreted this as an intelligent response to unacceptable learning conditions. Formal institutions (like school or university) and nonformal institutions (outofschool education) are only just beginning to acknowledge informal learning. Informal learning is mostly considered to only taking place almost in passing, in non-arranged, unorganized settings (Mack 2007). But, if there are opportunities for autonomous learning, young people are certainly encouraged to structure and organize their learning on a self-initiated basis and to set up an appropriate framework for it. It was exactly this kind of learning that took place in the tenant projects, and this should be regarded as a key educational ability: the ability to let your actions be guided by individual concerns and the needs of the community. The tenants purposefully worked towards and achieved selfdetermination (e.g. by engaging with politics), selforganization (e.g. by structuring their involvement) and selfregulation (e.g. by getting ethically concerned).

Our power lab theorized an environmental approach to educational practice and aimed to connect learning to real life situations and to things that matter to the learner. We shifted the focus from a teacheroriented transfer of knowledge to informal learning in urban neighborhoods (Steffen 2010). This perspective allowed us to emphasize knowledge as something negotiated in situ, where people connect via social practices in leisure and working activities and within "communities of practice" (Wenger-Trayner 2015). Here, the use of the word environment not only intends to convey the idea of social, economical and ecological benefits for sustainable development, but is understood as a stimulating field in which learning is an evolving, continuously regenerated set of practices. It allows people to take possession of their needs and shape the world by their kinaesthetic and critical thinking abilities, while being involved in their sitespecific activities. The tenant project fostered such an environmental approach. Its effectiveness is reflected by the fact that the young tenants mastered their selfgenerated demands and began to appreciate the importance of other tenants' contributions and those of the community, thus showing an increasing engagement with others. The project triggered learning opportunities by providing spaces on the condition that the tenants engage with the public. In doing so they energized their immediate environment and made 


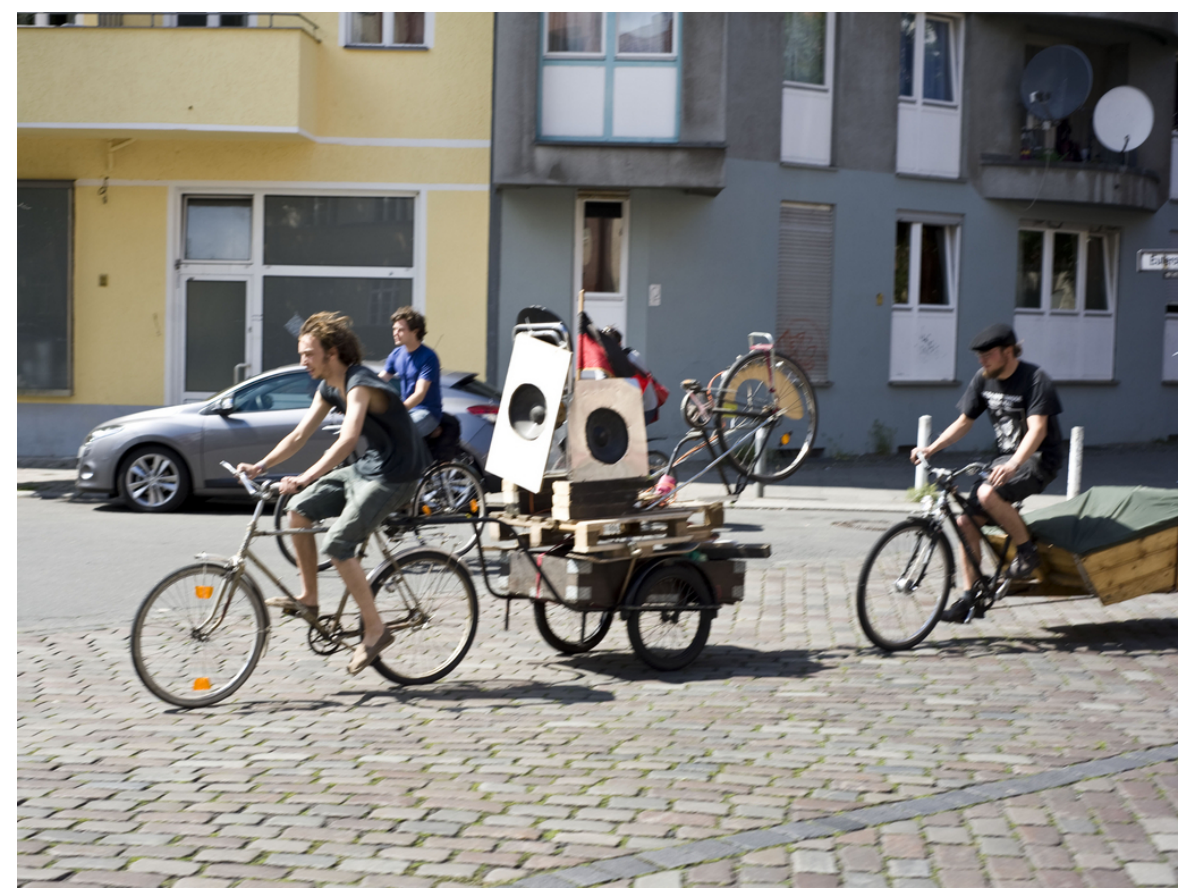

Figure 5: Fig. 5. "Knight riders", clearing a passage to the demo (@ Schlesische27).

creative contributions to the use of the urban sphere. Such an approach calls for facilitators who, like agents, build bridges, mediate and connect people who otherwise would not meet. Such facilitators only get involved on request, unless they decide it is necessary to intervene. This may happen when a group has reached a point of complacency or stagnation. Interventions take the form of artistic impulses and rely on non-discursive presentational, aesthetic settings. Such interventions can help to spur on the group's selfdetermined activities and encourage the young people to become more involved in art making or community life and, ultimately, contribute to the empowerment of young people.

Junipark // In June 2014 the last cycle ends. It's time to clear the way for new projects. The situation in Berlin has changed since the kickoff in 2011. Finding spaces for selforganized artistic and cultural work is still a problem but even worse are the general living conditions in contemporary Berlin. The tenants feel that the increasing gentrification will gradually lead to the social marginalization of young people. For the final event they want to have an extravaganza, - the socalled "Juniversum" - to express their 'Wohnwut' (anger about housing development plans) and to discuss visions for an affordable, good and sustainable urban life. And, as an aside, they want to make their presence felt at the nationwide "Youth Assistance Day", held every three years in a different city: in 2014 in the trade fair halls in Berlin. The architects of Raumlabor intervened and installed a house-sized metal scaffold, several storeys high, right next to the Tempelhofer Feld (a former airport in the heart of Berlin that is now being used as a public park, but whose future use is highly 
disputed). It consists of basic architectural structures, cubic spaces (of which some are separated by a white scaffolding net), one big enough to serve as a theatre arena, another one used as a kitchen, and the smaller roomsized ones are the last location for all the tenants coming from the spaces in the different districts to meet, give workshops, organize exhibitions, create theatre, etc.

At one point the members of the invited youth theatre group "Die Zwiefachen" (from Schaubühne Berlin) suddenly turn into zombies and start to occupy the surrounding field. "They squeeze all the breath out of you, plan luxury apartments on Tempelhofer Feld," says the narrator of the show. "But don't get upset. We've done research and know how to deal with this 'Zombiefication'. We'll dig a giant hole, flood it and drown them. Zombies can't swim."

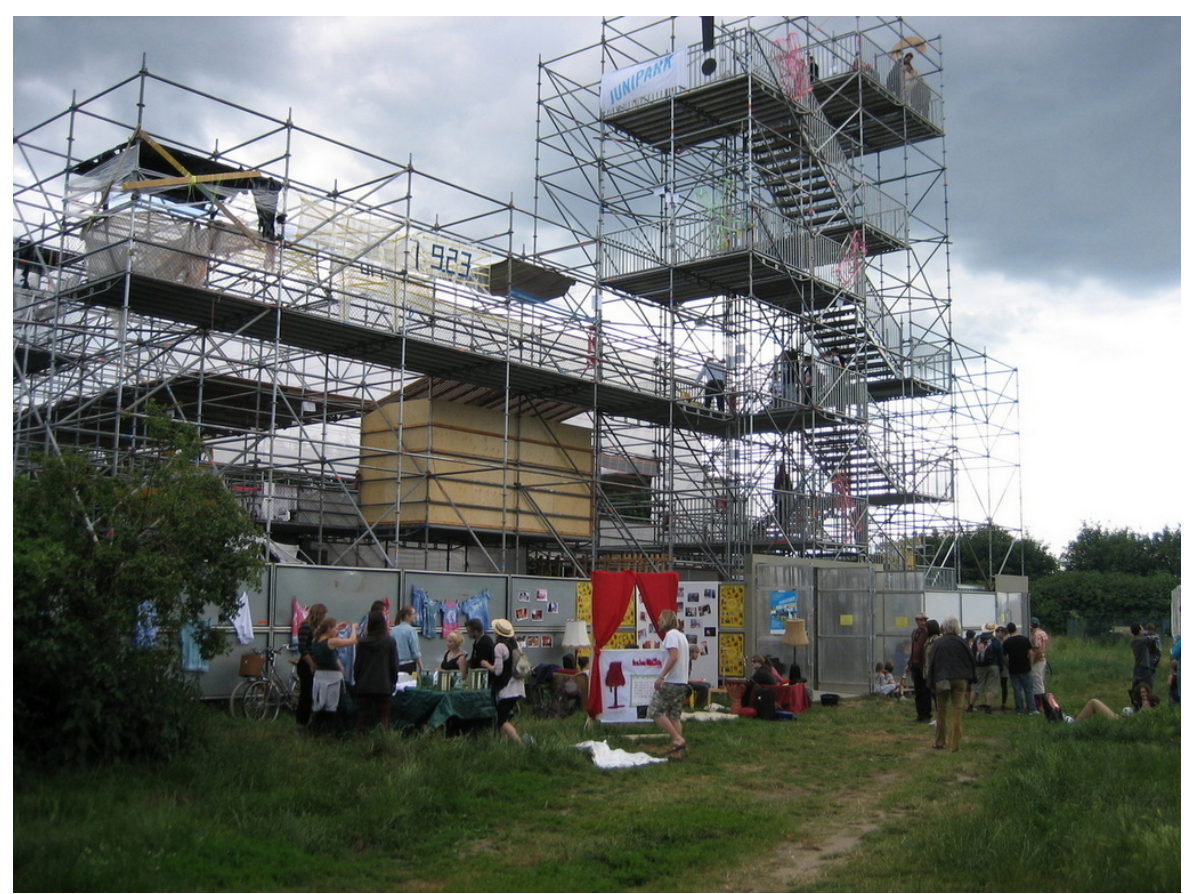

Figure 6: Fig. 6. "Juni Park", the tenant's last domicile on Tempelhofer Feld (@ Hanne Seitz).

\section{Implications and afterthought}

Whether we want to or not, for quite some time now we have become a performance society (McKenzie 2001, Seitz 2014). Performance not only extends to the areas of theatre, music and other cultural activities, but the term also covers forms of organizational and technical practice as well as the theatricality of our daily lives. There is a constant pressure to perform and, consequently, to evaluate, measure, compare and assess the levels of achievement of individual people and institutions. All kinds of data are exploited in order to improve practices and achieve optimal results and effective management. Against this 
background it is not surprising that research in general has also become a key issue in the social, cultural and educational area and that our research on the tenants inevitably contributed to this development, particularly through emphasizing performative research. It is already being discussed how informal learning achievements can be made creditable within the formal educational system (Werquin 2010). Tenants from Machwerk, for example, who ask "Why is the classroom the main place where lessons take place?" would be delighted to get credit points for their 'knightrider' invention. This feels like a dilemma. Our research did not address the young people as if they were a closed book full of 'data' waiting to be decoded and assessed. But, as researchers we located and examined hidden knowledge and investigated intrinsic motivation, thus running the risk of making artistic experiences usable and exploitable. The tenant project empowered young people by giving them open spaces for creative use and the research shed light on the goingson on the premises. But the latter not only produced knowledge relevant for the young people, the outcomes might also be relevant for the neoliberal economy.

Once they are given the opportunity, young people tend to become creative, independent, responsible and ethically concerned, and they create networks and structures for participation and selfempowerment. In retrospect there is reason to assume that they will, now that the project has come to its end, take further steps, remain critically aware, continue to risk subversive thinking, and maintain the waywardness of art. The tenants practiced what in German is termed 'Selbstbildung', which refers to the essential interplay between feeling, thinking and will, between self, others and the environment. Regardless of whether it is in the educational, social or political arena, it is all about the art of doing, especially, as here, in selfinitiated environmental approaches to artistic practices. "The magic is in handling." (Barrett \& Bolt 2007)

\section{Bibliography}

Altrichter, Herbert et al. (2008): Teachers investigate their work. An introduction to action research across the professions. London: Routledge

Bolt, Barbara (2007): The Magic is in Handling. In: Barrett, Estelle \& Bolt, Barbara (eds.): Practice as Research. Approaches to Creative Arts Enquiry. London: I. B. Tauris, 27-34

Haseman, Bradley C. (2007): Rupture and Recognition: Identifying the Performative Research Paradigm. In: Barrett, Estelle \& Bolt, Barbara (eds.): Practice as Research. Approaches to Creative Arts Enquiry. London: I.B. Tauris, $147-157$

Kulturprojekte Berlin (2010): Kunst und Kultur in Berlin - Was geht mich das an? Jugendliche befragen Jugendliche. Berlin.

http://www.kulturprojekte-berlin.de/kulturelle-bildung/kuensteschule.html [last accessed June 20, 2015] 
Langer, Susanne K. (1957): Philosophy in a New Key: A Study in the Symbolism of Reason, Rite and Art. Cambridge, MA.: Harvard University Press.

Mack, Wolfgang (2007): Lernen im Lebenslauf - formale, nonformale und informelle Bildung. Düsseldorf.

McKenzie, Jon (2001): Perform or Else: From Discipline to Performance. London: Routledge

Seitz, Hanne \& Steinkrauss, Nils (2013): Machwerk, Heim(e)lich \& Co. Urbane SpielRäume für junge Leute. In: Jörissen, Benjamin \& Westphal, Kristin (eds.): Vom Straßenkind zum Medienkind. Raum und Medienforschung im 21. Jahrhundert. Weinheim: Juventa.Beltz, 81-95

Seitz, Hanne (2012): Performative Research. In: Fink, Tobias et al. (eds.): Die Kunst, über Kulturelle Bildung zu forschen. München: Kopaed, 233247

Seitz, Hanne (2014): Zuschauer bleiben, Publikum werden, Performer sein. Modi der Partizipation. In: Pinkert, Ute (ed.): Theater Pädagogik am Theater. Kontexte und Konzepte von Theatervermittlung. Schibri: Milow/Strasburg/Berlin, 79-89

Steffen, Gabriele (2010): Informelle Lerngelegenheiten im Stadtteil. In: Informationen zur Raumentwicklung 2/3.

http://www.b.bsr.bund.de/BBSR/DE/Veroeffentlichungen/IzR/2010/ 2_3/Inhalt/inhalt.html [last accessed June 20, 2015]

Wenger-Trayner, Etienne \& Wenger-Trayner, Beverly (2015): Communities of practice - a brief introduction. http://wenger-trayner.com/ resources/ [last accessed June 20, 2015]

Werquin, Patrick (2010): Recognition of Nonformal and Informal Learning. http://www.die-bonn.de/id/4276/about/html/ [last accessed August 10, 2015]

Whitehead, Jack (2015). The Practice of Helping Students to Find Their First Person Voice in Creating Living-Theories for Education. In: Bradbury, Hilary (ed.): The SAGE Handbook of Action Research ( ${ }^{\text {rd }}$ ed.). London: Sage, 246-254

Internet: 
Hanne Seitz

Producing Knowledge in Self-Organized Artistic Settings through

Scenario

Performative Research and Artistic Intervention

Volume $2015 \cdot$ Issue 1

www.etfu.eu [last accessed August 10, 2015]

Www.fh-potsdam.de/projekt/project-action/show/Project/etfu-empowering-

the-future-youth-arts-media/ [last accessed August 10, 2015]

www.junge-paechter.de [last accessed August 10, 2015] 